Article

\title{
Study on the Preparation of High-Temperature Resistant and Electrically Insulating h-BN Coating in Ethanol Solution by Electrophoretic Deposition
}

\author{
Kun Jia $\mathbb{D}^{-}$, Xu Meng and Wei Wang * \\ Department of Applied Chemistry, School of Chemical Engineering and Technology, Tianjin University, \\ Tianjin 300072, China; 2018207403@tju.edu.cn (K.J.); mxmengxu@tju.edu.cn (X.M.) \\ * Correspondence: wangweipaper@tju.edu.cn
}

Citation: Jia, K.; Meng, X.; Wang, W. Study on the Preparation of

High-Temperature Resistant and

Electrically Insulating h-BN Coating in Ethanol Solution by Electrophoretic Deposition. Processes 2021, 9, 871.

https://doi.org/10.3390/pr9050871

Academic Editor:

Anna Paola Caricato

Received: 12 April 2021

Accepted: 14 May 2021

Published: 15 May 2021

Publisher's Note: MDPI stays neutral with regard to jurisdictional claims in published maps and institutional affiliations.

Copyright: (c) 2021 by the authors. Licensee MDPI, Basel, Switzerland. This article is an open access article distributed under the terms and conditions of the Creative Commons Attribution (CC BY) license (https:// creativecommons.org/licenses/by/ $4.0 /)$.

\begin{abstract}
A hexagonal boron nitride (h-BN) coating of micron thickness is deposited directly on 316L stainless steel (SS316L) cathode through efficient, adjustable electrophoretic deposition (EPD) in a suspension system containing surfactant and ethanol. It is based on the mixing of h-BN with polyethyleneimine (PEI) resulting in positively charged ceramic powder making cathodic electrophoretic deposition possible. The thickness of the resulting h-BN coatings deposited on SS316L could be controlled by varying the time and the voltage of electrophoretic deposition. The deposition kinetics and mechanism have been discussed. After soaking in $\mathrm{Al}\left(\mathrm{H}_{2} \mathrm{PO}_{4}\right)_{3}$ solution and high-temperature annealing, the h-BN coatings exhibited good adhesive strength. Furthermore, a novel method has been used for the evaluation of the adhesive strength to explore the appropriate experimental conditions. X-ray diffraction spectroscopy (XRD), Fourier transform infrared spectroscopy (FTIR), scanning electron microscopy (SEM) and energy dispersive spectroscopy (EDS) were employed to characterize the h-BN coatings. The h-BN coatings are applied for the DC breakdown performance test and exhibit remarkable breakdown voltage and breakdown strength.
\end{abstract}

Keywords: electrophoretic deposition; hexagonal boron nitride; coating; aluminum dihydrogen phosphate; electrical insulation

\section{Introduction}

In response to the ever-increasing climate change, the use and transmission of clean energy have become a primary focus for the industry and the scientific community. As a form of energy that is widely used and environmentally friendly, electricity gives great hope for a better future for mankind. There has been increasing interest in long-distance power transmission equipment. Electrical steel with high magnetic induction and mechanical properties is an important component of transformers and electronic components [1-3]. To reduce eddy current losses, the coatings have been applied to the surface of electrical steel sheets to prolong the service life of the device [4,5]. Such coatings should exhibit good adhesion and insulation properties to meet the requirements of equipment for components. The heat resistance and heat dissipation of coating material, furthermore, is considered to pose a great deal of help to the use of electrical steel due to overheating issues at high voltage [6,7].

In the previous studies, several different methods have been developed, such as the solgel method [8], spray method [9], dipping method [10], vapor deposition method [11] and so on. While the traditional dipping method for industrial production is dominating the market, they suffer from many drawbacks originating from non-uniformity of the coating and high energy consumption. Besides, large-scale applications of the vapor deposition method are not feasible due to their complexity and high cost. These methods, such as spraying and the sol-gel method, cannot enable efficient control over the structure of the coatings and rate of qualified products at a low processing cost, and cannot be employed 
extensively in the coating industries. In recent years, DC electrophoretic deposition (EPD) has attracted tremendous research interest as an efficient preparation method. Compared with the several methods introduced before, it has the advantages of simpler equipment, more convenient operation and the ability to control the thickness of the coating. EPD can not only be applied to the suspension of ceramic particles but can also be used to deposit polymers [12], graphene [13], and biological materials [14]. Prior to EPD, various powders are suspended in an electrophoretic solvent containing surfactants to form a colloidal solution. The EPD process drives particulate materials in a solvent towards substrate with an applied electric field $[15,16]$. Although the preparation of the coating can be controlled by the deposition voltage and time, the EPD process still needs to be carried out in a solvent with a higher decomposition voltage. In this system, surfactants that provide effective surface charge to the particles have also been considered in detail [17]. These considerations become particularly important.

Hexagonal boron nitride (h-BN), an artificially prepared material with a two-dimensional (2D) nanostructure, has attracted much attention in ceramic coating research [18,19]. In a two-dimensional plane, boron atoms and nitrogen atoms are covalently bonded; van der Waals forces exist in these two plane layers [20]. It has been widely recognized as a promising ceramic material for coatings as it carries many superior properties, including exceptional thermal stability, optimal anti-oxidation, and excellent electrical insulation properties [21]. The reason why h-BN is used as the main component of the coating is that: (1) the material itself has good insulation and oxidation resistance, which is beneficial to be used under more severe conditions; (2) the excellent thermal conductivity of h-BN can ensure heat dissipation and avoid damage to electrical steel; and (3) the excellent mechanical properties of h-BN are conducive to various complex processing [22].

The h-BN is being widely explored because of its layered structure and special surface properties. However, the surface of boron nitride is too stable to have a binding site to bond with a functional group $[23,24]$. To overcome this problem, surfactants have been used to modify the surface of boron nitride to enhance the wettability, dispersibility, and charge on the particle surface in the solvent. According to related literature [25], we found that common cationic surfactants with only a single charge can hardly meet the above requirements. Therefore, polyethyleneimine (PEI) has become a suitable choice, which owes its advantages to a large number of amino groups and good solubility in ethanol.

To reduce the eddy current loss caused by hard magnetic materials in use, herein, we report the facile electrophoretic deposition of hexagonal boron nitride on 316L stainless steel as an insulation coating. We found that combining two low-cost materials, hexagonal boron nitride and phosphate, it is possible to obtain an insulation coating with controllable thickness and high-temperature resistance. We produced coatings with good adhesion and breakdown properties. The direct deposition of hexagonal boron nitride 316L stainless steel would provide suitable structure and porosity, thus facilitating the diffusion of phosphate ions, improving the tightness of the coating, the adhesion between the particles and the insulation performance.

\section{Materials and Methods}

\subsection{Preparation of Solution}

A total of $0.1 \mathrm{~g}$ of $\mathrm{h}-\mathrm{BN}$ was dispersed in $50 \mathrm{~mL}$ of ethanol with different $\mathrm{pH}$ and dispersed through ultrasonication for $0.5 \mathrm{~h}$. These suspensions of h-BN were magnetically stirred for 12 h. Acetic acid (99.9\%, Sinopharm Group, Shanghai, China) and sodium hydroxide (99.6\%, Sinopharm Group, Shanghai, China) were used as the pH regulators of the suspension. The digital display $\mathrm{pH}$ meter was used as an indicator for $\mathrm{pH}$ adjustment. A series of ethanol suspension containing $0.1 \mathrm{~g}$ of $\mathrm{h}-\mathrm{BN}$ powder and polyethyleneimine (PEI, 99.9\%, M.W.10000) (Aladdin, Shanghai, China) was prepared. The concentrations of PEI varied from 0.1 to $0.8 \mathrm{~g} / \mathrm{L}$. The $\mathrm{pH}$ of these suspensions was adjusted to 4 with acetic acid. These suspensions were dispersed through ultrasonication for $0.5 \mathrm{~h}$ and 
magnetically stirred for $12 \mathrm{~h}$. The supernatant of all of the suspensions was taken out for the measurement of zeta potential after standing for $12 \mathrm{~h}$.

A suspension containing $2 \mathrm{~g} / \mathrm{L}$ of h-BN, $0.4 \mathrm{~mol} / \mathrm{L}$ of PEI and $500 \mathrm{~mL}$ of ethanol was adjusted to $\mathrm{pH}=4$ with acetic acid. The suspension was used for electrophoretic deposition of the insulating coating after dispersion for $0.5 \mathrm{~h}$ and magnetic stirring for $12 \mathrm{~h}$.

The $\mathrm{pH}$ of the suspension was measured with a $\mathrm{pH}$ meter (Leici PHS-3E, Shanghai, China) at $25{ }^{\circ} \mathrm{C}$. Due to the lack of standard buffer solutions for ethanol three aqueous standards of $\mathrm{pH}=4.00,6.86$ and 9.18 were used for standardization. Thus, the so-called "operational $\mathrm{pH}$ values" of a non-aqueous suspension can be directly read by a $\mathrm{pH}$ meter [26].

$$
\mathrm{pH}=p a_{H}-\frac{\Delta E_{j}}{0.05916}\left(\text { at } 25^{\circ} \mathrm{C}\right)
$$

where $\mathrm{pH}$ is the $\mathrm{pH}$ meter reading, and $p a_{H}$ is the negative logarithm of the proton activity in a non-aqueous suspension. The $\Delta E_{j}$ is the residual liquid-junction potential. For the ethanol suspension, $\left(\Delta E_{j} / 0.05916\right)=1.23$. [26]. In this paper, the uncorrected $\mathrm{pH}$ read by the $\mathrm{pH}$ meter was used for convenience.

\subsection{Preparation of $h-B N-P E I$ Samples}

A total of $20 \mathrm{~mL}$ of h-BN suspension for deposition was taken out and centrifuged for $10 \mathrm{~min}$ at a speed of $8000 \mathrm{r} / \mathrm{min}$. After centrifugation, the precipitate was washed with ethanol and centrifuged several times. The processed precipitate was dried at $50{ }^{\circ} \mathrm{C}$ for $12 \mathrm{~h}$, and the dried sample was used to test.

\subsection{Surface Treatment of the Substrate}

Electrodes consisted of $40 \times 10 \times 0.01 \mathrm{~mm}$ SS316L sheet were polished with sandpaper with a grain size of 1000 and 2000, and were electrochemically degreased in an alkaline solution at $70{ }^{\circ} \mathrm{C}$ for $10 \mathrm{~min}$. These electrodes were thoroughly washed with deionized water, dried and weighed on a microbalance. Polyimide tapes were used to encapsulate these electrodes, and the same area of $20 \mathrm{~mm} \times 10 \mathrm{~mm}$ was exposed.

\subsection{Electrophoretic Deposition and Post-Processing of Sample}

The EPD process parameters were given in Table 1. SS316L was used as the working electrode and counter electrode. The prepared h-BN suspension was ultrasonicated for $30 \mathrm{~min}$ before use. The two electrodes were placed parallel to each other in a two-electrode cell and were separated by a distance of $10 \mathrm{~mm}$. After depositing the coatings at $25^{\circ} \mathrm{C}$, the samples were placed in a drying oven followed by drying at $50^{\circ} \mathrm{C}$ for $12 \mathrm{~h}$. The dried samples with the packaging tape removed were weighed on an analytical balance.

Table 1. Conditions for electrophoretic deposition.

\begin{tabular}{cc}
\hline Deposition Voltage (V) & Deposition Time (min) \\
\hline $15,20,30,40,50$ & $2,4,6,8,10,12,14,16$ \\
\hline
\end{tabular}

Subsequently, the coating samples were placed in the prepared aluminum dehydration phosphate $\left(\mathrm{Al}\left(\mathrm{H}_{2} \mathrm{PO}_{4}\right)_{3}, 99.9 \%\right.$, Aladdin, Los Angeles, $\left.\mathrm{CA}, \mathrm{USA}\right)$ aqueous solution and soaked at $25{ }^{\circ} \mathrm{C}$ for $12 \mathrm{~h}$. The sample was placed in a tube furnace and heat-treated in a nitrogen atmosphere after the immersion. The samples were annealed at 100, 200 and $400{ }^{\circ} \mathrm{C}$, respectively, for $2 \mathrm{~h}$, using a heating rate of $5^{\circ} \mathrm{C} / \mathrm{min}$.

\subsection{Characterization}

All prepared samples of h-BN suspension were used to determine the zeta potential of the particles in ethanol at $25^{\circ} \mathrm{C}$. Each sample was tested three times with a zeta potential meter (Nano ZS, Malvern, UK) and the average was taken. 
XRD analysis was performed on the powder and samples to determine the substance and showed the crystal phase state of the coating surface. XRD patterns were obtained with an X-ray diffractometer (D8-Focus, Bruker, Germany) with CuK $\alpha$ radiation $(\lambda=1.5419 \AA)$, in the $2 \theta$ range of 20 to $60^{\circ}$ with a scan speed of $4^{\circ} / \mathrm{min}$.

Coatings and suspension were analyzed by Fourier infrared transform spectroscopy (Nicolet 6700, Nicoli, MA, USA), with potassium bromide as a reference, in the wavenumber range of 500 to 4000 .

The morphology of all coatings was analyzed by using a scanning electron microscope (SEM), and the elements were analyzed by energy dispersive spectroscopy (EDS). The coatings were observed by using a projection electron microscope.

An ultrasonic oscillation (KQ-300B, Jiangsu, China) was employed to evaluate the adhesive strength $(A d \%)$ between the coating and the steel substrate. The sintered samples ultrasonically oscillated for $30 \mathrm{~min}$ in deionized water at $300 \mathrm{~W}, 40 \mathrm{kHz}$, followed by drying and weighing. The expulsion rate $(E r \%)$ and adhesive strength of the coating were then calculated by the following equations [27].

$$
\begin{aligned}
& E_{r}(\%)=\frac{M_{1}-M_{2}}{M_{1}} \% \\
& A d(\%)=1-E_{r}(\%)
\end{aligned}
$$

where $M_{1}(\mathrm{~g})$ and $M_{2}(\mathrm{~g})$ are the quality of samples before and after ultrasonic treatment, respectively. In addition, the cross-test was used to test the adhesion strength of the coating prepared under different conditions according to the ASTM D3359-09-B.

Several coating samples were deposited at $30 \mathrm{~V}$ and $10 \mathrm{~min}$, and then immersed $\left(0.2 \mathrm{~mol} / \mathrm{L} \mathrm{Al}\left(\mathrm{H}_{2} \mathrm{PO}_{4}\right)_{3}\right)$ and annealed. Next, the samples were annealed in an environment filled with nitrogen and at different temperatures, with a heating rate of $5{ }^{\circ} \mathrm{C} / \mathrm{min}$.

A digital micrometer (AWT-CHY01, Henan, China) was used to test the thickness of the sample. Five points were measured for each sample, and the average value was taken. With a boosted rate of $0.1 \mathrm{kV} / \mathrm{s}$, a breakdown voltage tester (DDJT-50kV, Beijing, China) was used to test the breakdown voltage of the processed samples.

\section{Results and Discussion}

\subsection{Zeta Potential}

In this work, the surface electrical characteristic of the h-BN particles in ethanol is also investigated by zeta potential measurements, which changes as a function of $\mathrm{pH}$ values of the dispersion medium. As shown in Figure 1, the isoelectric point is achieved in the dispersion medium in the $\mathrm{pH}$ interval of 5 to 6 . When the $\mathrm{pH}$ is lower than the isoelectric point, then the positive zeta potential of the h-BN particles increases with the decrease of $\mathrm{pH}$, which is mainly caused by the adsorption of protons by h-BN. However, when the $\mathrm{pH}$ is higher than the isoelectric point, the negative zeta potential of the h-BN particles decreases with the increase of $\mathrm{pH}$. It may be ascribed to the introduction of acetate or hydroxide group. Generally, if the absolute value of the zeta potential of the particles is greater than $30 \mathrm{mV}$, the suspension is considered to be stable for a long time. As mentioned in Figure 1, the suspension cannot remain stable by adjusting the $\mathrm{pH}$, requiring the addition of an appropriate amount of PEI. 


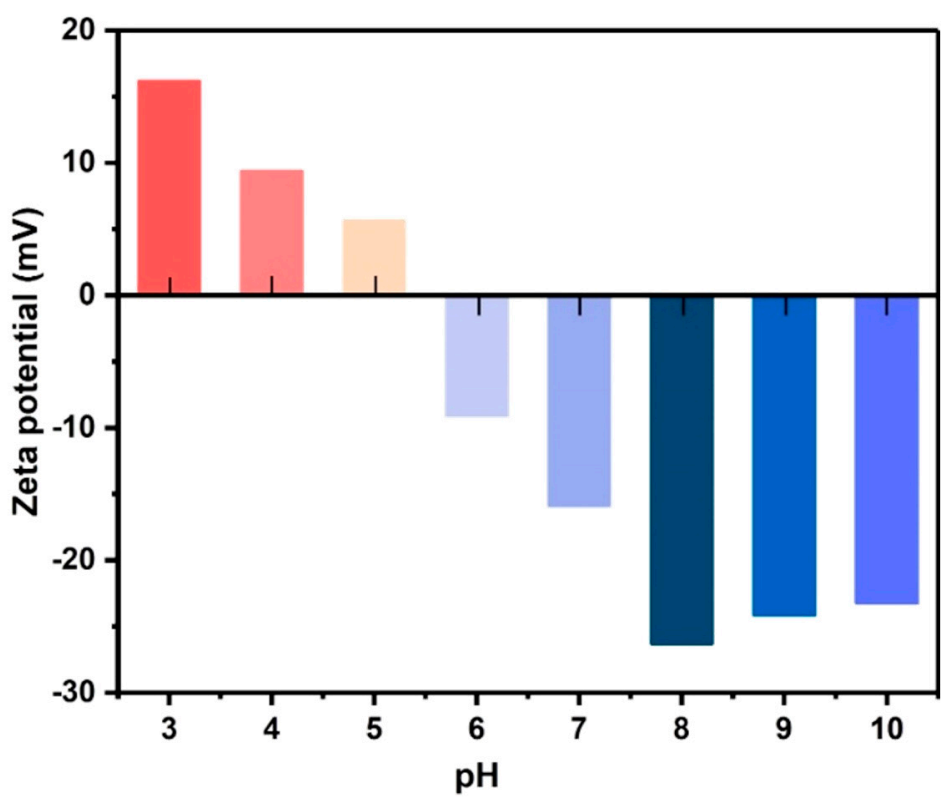

Figure 1. Zeta potential of h-BN particles as a function of $\mathrm{pH}$ for pure ethanol suspension.

To further identify the impact of PEI concentration at $\mathrm{pH} 4$, the surface charge conditions of the h-BN/PEI particles were monitored by the zeta potential. The result of zeta-potential charge analysis of the h-BN/PEI particles is shown in Figure 2. The results indicate that the zeta potential increases with the concentration of PEI from 0.1 to $0.4 \mathrm{~mol} / \mathrm{L}$, and then decreases with the concentration higher than $0.4 \mathrm{~mol} / \mathrm{L}$. The highest potential of the h-BN/PEI particles reaches $38.1 \mathrm{mV}$. The h-BN/PEI particles show an extensive positive zeta potential over a suitable $\mathrm{PEI}$ concentration range, which is predominantly due to the amine groups carried by PEI. Through the acid-base interaction, large amounts of PEI molecules are better accommodated on the surface of the h-BN particle, which contains electron-deficient boron atoms [28]. As mentioned in Figure 3, the h-BN/PEI particles contain large quantities of residual amine or imine groups liable to be protonated under acidic conditions, thus causing the particles to carry a highly positive charge density [29]. However, an excessively high PEI concentration can cause bridging effects between the boron nitride particles, resulting in a decrease in zeta potential.

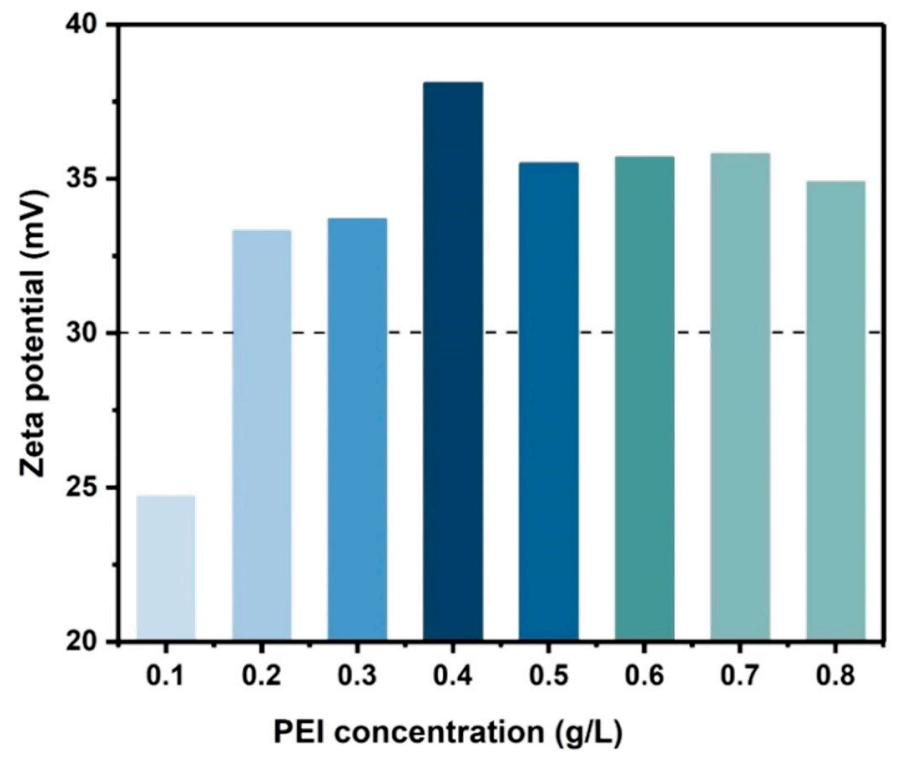

Figure 2. Zeta potential of h-BN particles as a function of PEI concentration for ethanol suspension. 


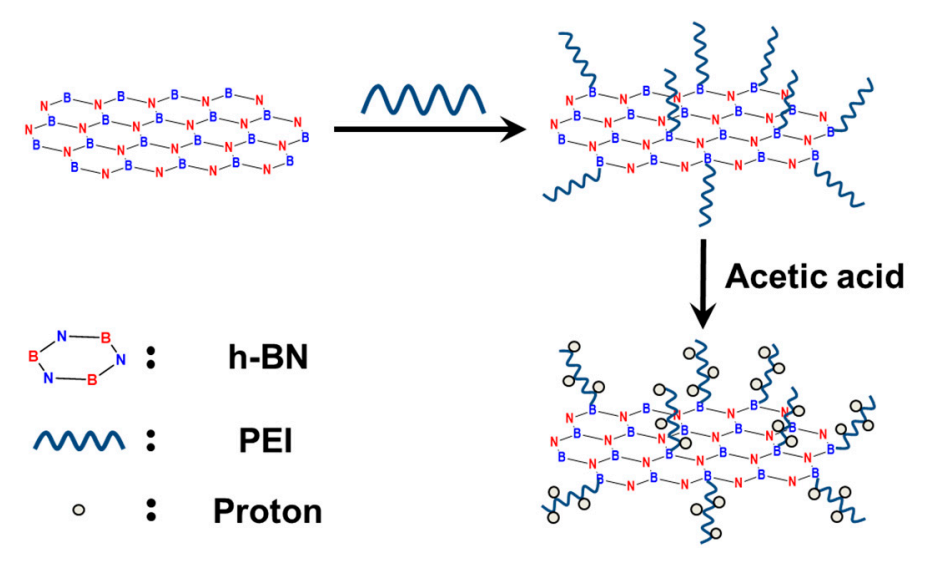

Figure 3. Synthesis scheme of the h-BN/PEI particles.

\subsection{XRD Patterns}

The structure of the h-BN particles, SS316L and coating sample was also characterized by XRD patterns, as shown in Figure 4. The five characteristic peaks displayed by the h-BN particles correspond to the diffraction peaks in the standard spectrum of h-BN. The coating sample displays a diffraction peak at the left end of the spectrum, which corresponds to (002) planes of the hexagonal crystal of h-BN [30]. It suggests that the structure of the h-BN particles is not destroyed after electrophoretic deposition. The remaining two diffraction peaks of the coating sample correspond to the two diffraction peaks of SS316L, indicating that the stainless steel is not affected by the deposited coatings.

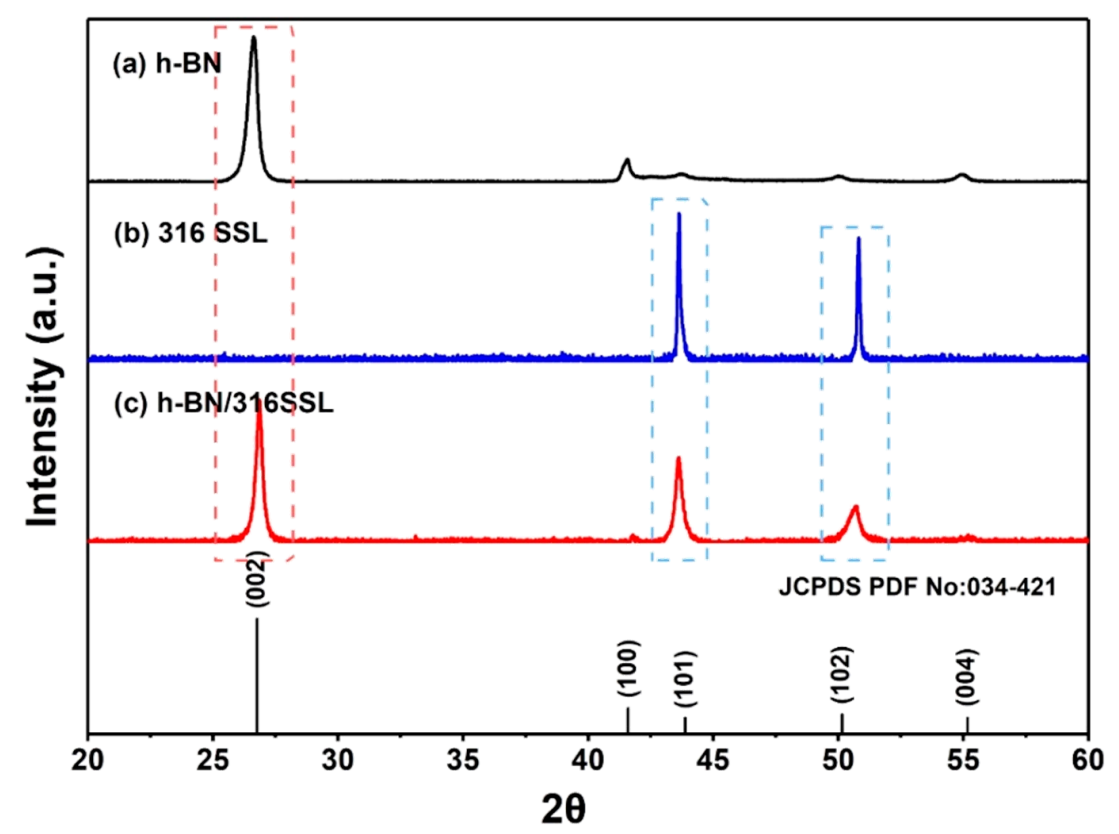

Figure 4. XRD patterns of (a) pure h-BN particles, (b) SS316L, (c) coating prepared by EPD using $30 \mathrm{~V}$ and $10 \mathrm{~min}$.

\subsection{FTIR Spectra}

To ensure the successful adsorption of PEI into the h-BN particles, the FTIR spectra of PEI, the h-BN particles and the h-BN-PEI sample were collected, as shown in Figure 5. The spectrum of the h-BN particles with no adsorption shows predominant peaks at $1388 \mathrm{~cm}^{-1}$ and $804 \mathrm{~cm}^{-1}$. These are two typical peaks that are caused by the in-plane $\mathrm{B}-\mathrm{N}$ transverse optical modes of the sp2 bonded $\mathrm{BN}$ and the B-N-B out-of-plane bending vibration [31]. Compared to the h-BN particles, new peaks of the h-BN-PEI sample at 
$3392 \mathrm{~cm}^{-1}, 3320 \mathrm{~cm}^{-1}, 2919 \mathrm{~cm}^{-1}$ and $2848 \mathrm{~cm}^{-1}$, representing $-\mathrm{NH}_{2}$ [32] and $-\mathrm{CH}_{2}$ group [33], indicate that PEI was successfully adsorbed on the h-BN particles.

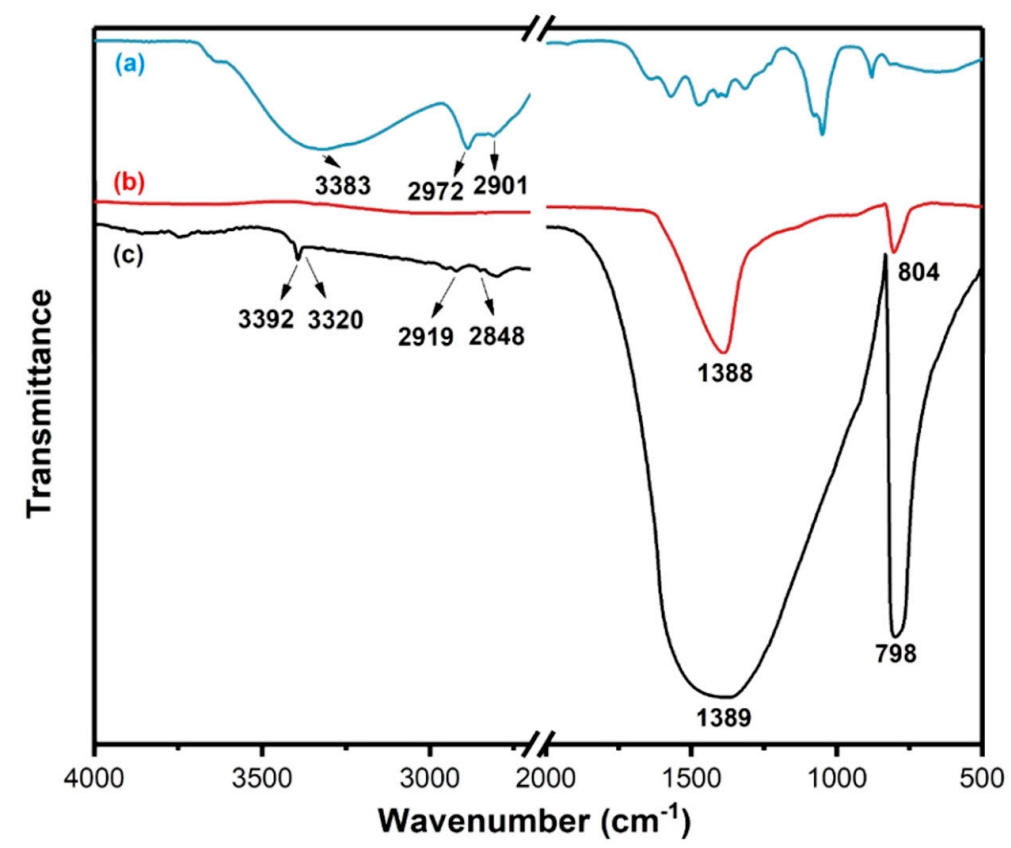

Figure 5. FTIR spectra patterns of (a) PEI, (b) pure h-BN particles and (c) h-BN-PEI.

\subsection{Weight Deposition Curves}

Figure 6 shows the mass-per-unit area of the PEI modified h-BN coatings deposited onto stainless steel after EPD at different voltages. The deposition process for the EPD can be seen in Figure 7. While the mass per unit area is continuously increasing at fixed voltage as the deposition time increases, the slope of the deposition curve is gradually decreasing. It is attributed to the shielding effect of the deposited coating on the electric field and the h-BN particles with slowed migration. Furthermore, the mass per unit area increases with the increase of the deposition voltage in the same time frame due to the faster migration and deposition of particles at the higher voltage.

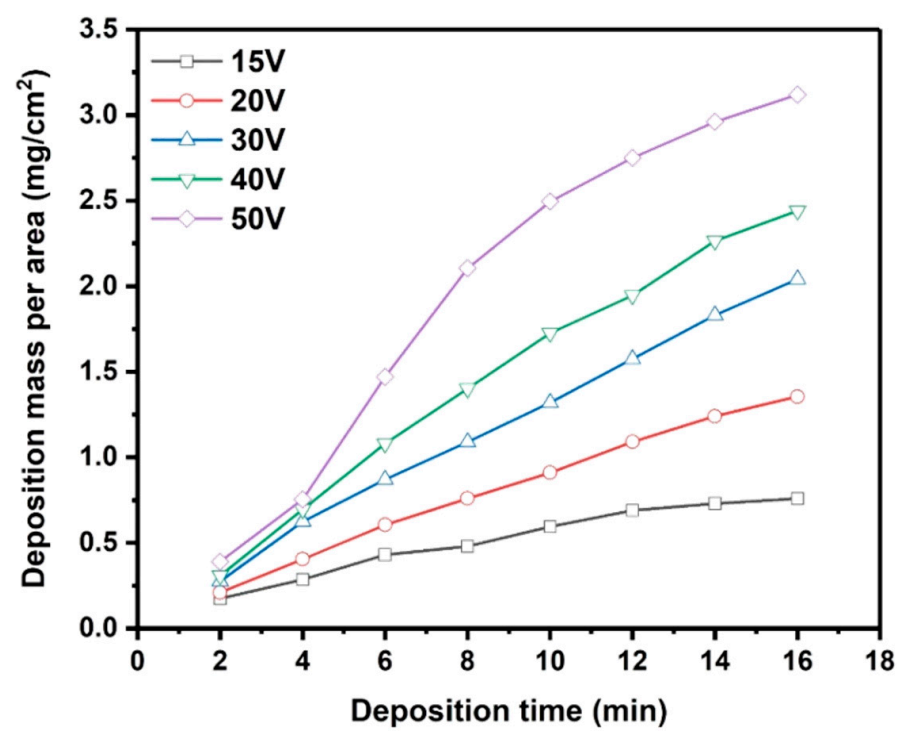

Figure 6. Deposition mass per unit area is a function of different times under different deposition voltages. 


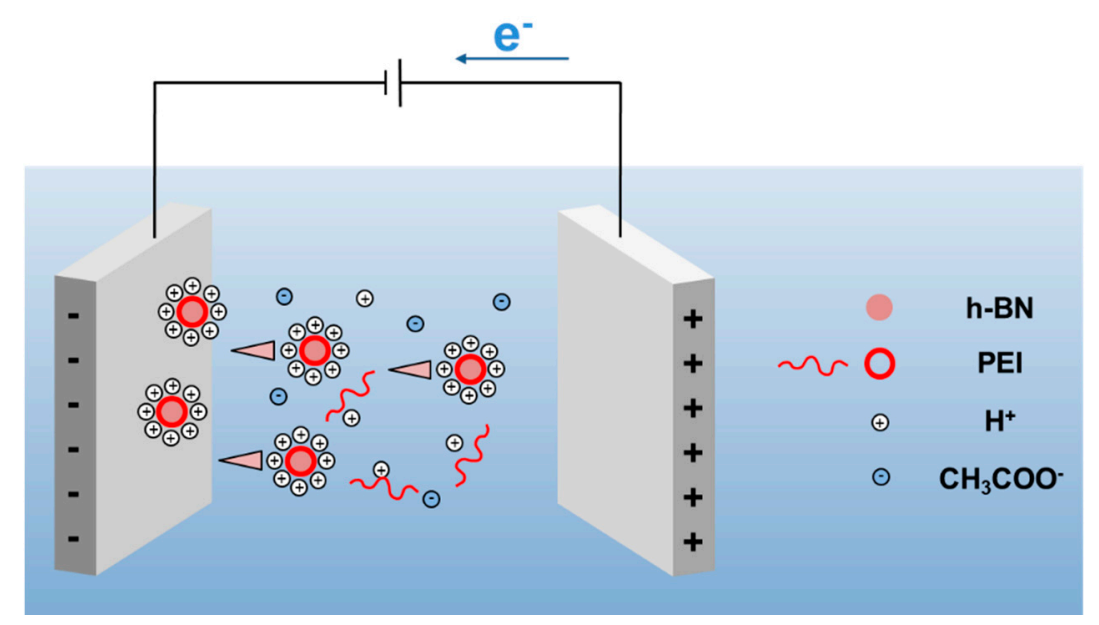

Figure 7. Deposition process of h-BN/PEI particles.

Increasing the voltage from 15 to $50 \mathrm{~V}$ resulted in a higher deposition yield, which is in rough agreement with the prediction of Hamaker's equation [34]:

$$
W=\mu C_{s} E A t
$$

where $W$ is the mass deposition, $\mu$ is the particle electrophoretic mobility, $E$ is the electric field, $t$ is the deposition time, $A$ is the surface area of the electrode, and $C_{S}$ is the concentration of colloidal particles in suspension. The changes in the particle concentration and conductivity caused by long-term deposition can limit the conditions of use of this equation. causing the mass curve at the same voltage not to follow the Hamarck equation.

\subsection{SEM and EDS}

SEM was used to investigate the surface morphology of the h-BN coatings without the added binder. Figure 8 shows the SEM images of the h-BN coatings prepared under different deposition conditions via EPD. With the increase of voltage within the same EPD time, the coating becomes more uneven and cracks are also visible, as shown in Figure 8a-c. On the microscale, the coating deposited at higher voltage is more prone to contain more pores. This is attributed to the fact that the migrated flake particles are deposited on the SS316L cathode with a non-compact spatial state at the higher voltage. The increase of porosity in the coating leads to the appearance of continuous cracks. The SEM images of the coatings with different magnifications displayed in Figure $8 \mathrm{~d}-\mathrm{f}$ show that the coatings deposited during different times at the same voltage. Obviously, it can be observed from the images that the unevenness of the coating surface becomes more obvious with increasing deposition times. Besides, the membrane surface exhibits a non-dense structure with some aggregates of the h-BN particles, which is mainly attributed to the shielding effect of deposited coating and shedding of particles with non-compact deposition for a long time. Figure 9 shows more related mechanisms in detail. As seen from Figure 10, the coating thickness decreases as the voltage and time increase. Repeated measurements of deposition thickness were carried out in all samples and the same results were observed. The tightness of the coating is thought to be related to EPD voltage and time too. Therefore, we can consider that the relevant explanation proposed has been proved. 

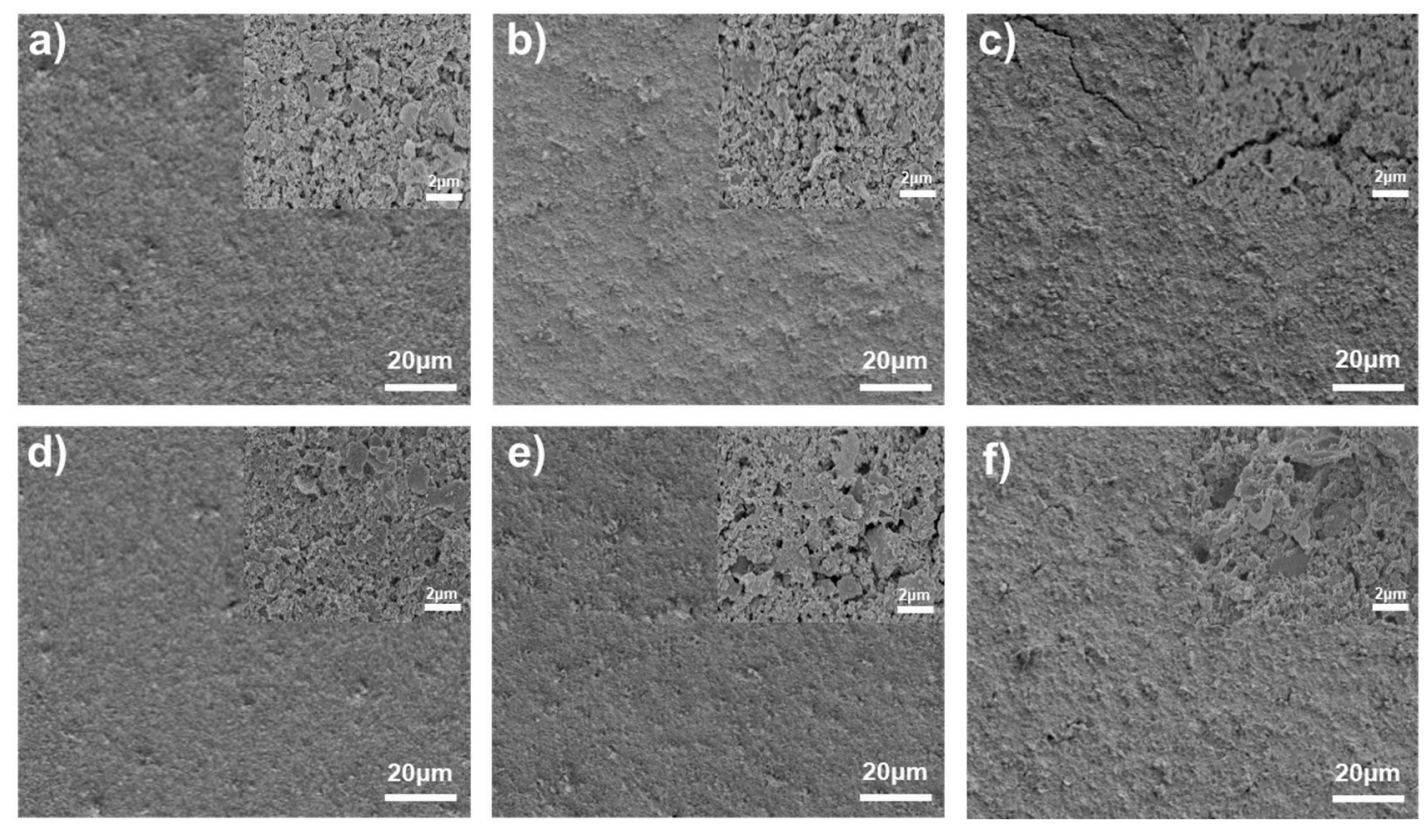

Figure 8. SEM images of untreated h-BN coatings under different deposition conditions. (a) $15 \mathrm{~V} 10 \mathrm{~min}$; (b) $30 \mathrm{~V} 10 \mathrm{~min}$; (c) 50 V $10 \mathrm{~min}$; (d) $30 \mathrm{~V} 8 \mathrm{~min}$; (e) $30 \mathrm{~V} 12 \mathrm{~min}$; (f) $30 \mathrm{~V} 16 \mathrm{~min}$.

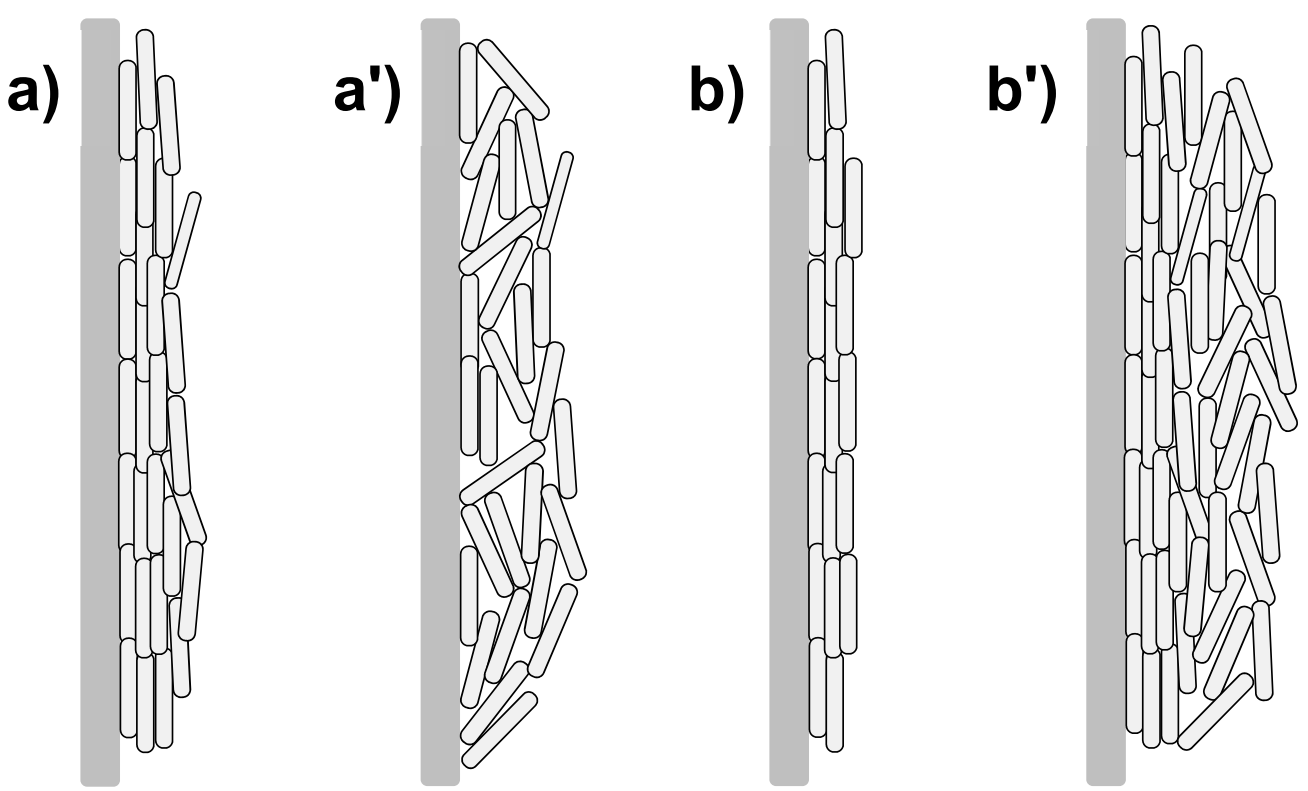

Figure 9. Deposition mechanism of boron nitride particles in the same time, under low voltage. (a) and high voltage (a'), and under the same low voltage for a short time $(\mathbf{b})$ and a long time $\left(\mathbf{b}^{\prime}\right)$. 

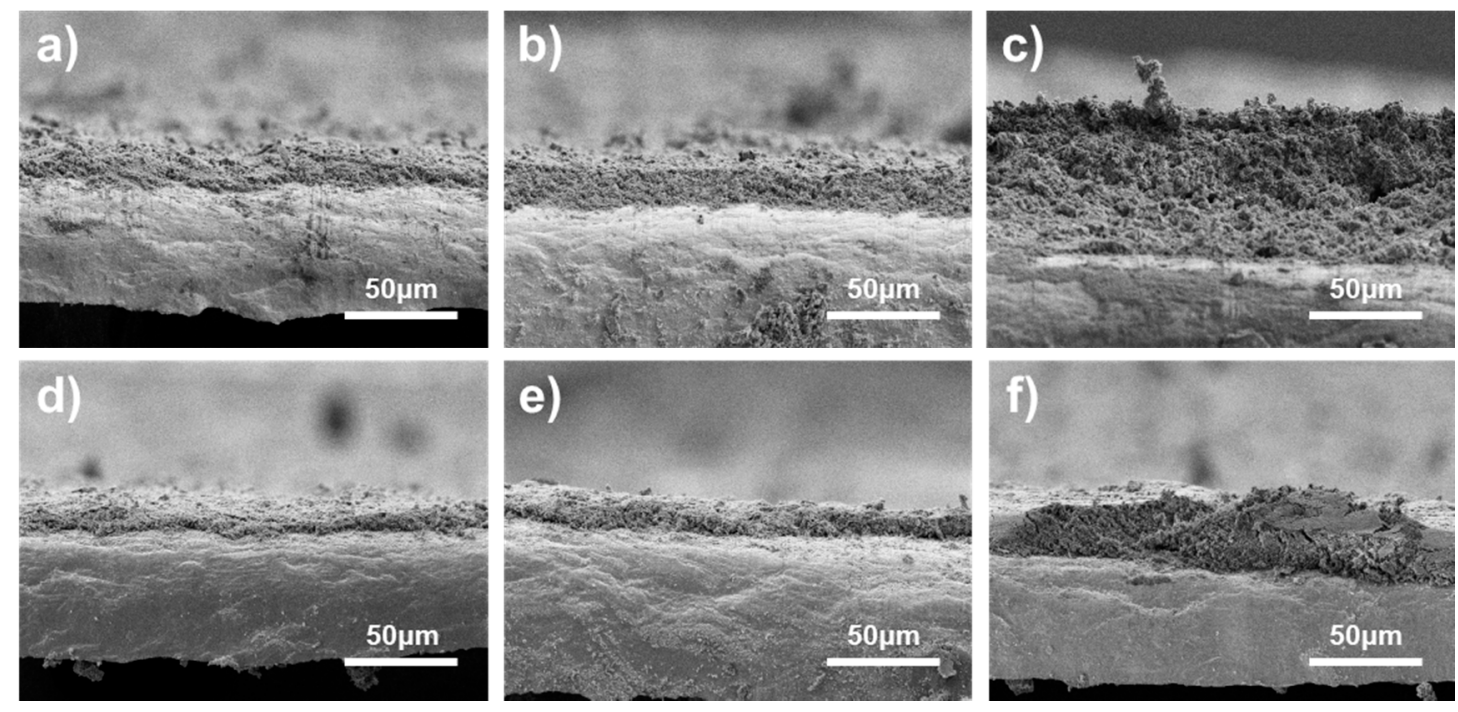

Figure 10. SEM images of the cross section of untreated h-BN coatings under different deposition conditions. (a) $15 \mathrm{~V}$ $10 \mathrm{~min}$; (b) $30 \mathrm{~V} 10 \mathrm{~min}$; (c) $50 \mathrm{~V} 10 \mathrm{~min}$; (d) $30 \mathrm{~V} 8 \mathrm{~min}$; (e) $30 \mathrm{~V} 12 \mathrm{~min}$; (f) $30 \mathrm{~V} 16 \mathrm{~min}$.

Figure 11 features the surface SEM images of annealed h-BN coatings soaked with $\mathrm{Al}\left(\mathrm{H}_{2} \mathrm{PO}_{4}\right)_{3}$ via the different deposition conditions. It can be observed from the image that the morphology of the treated coatings still follows the mechanism previously discussed. Comparing to the pristine coatings, Figure 11 shows the apparent distinction in the surface modified with post-treatment. The coating surface morphology with fewer and smaller pores confirms the diffusion of $\mathrm{Al}\left(\mathrm{H}_{2} \mathrm{PO}_{4}\right)_{3}$ into the coating. When the h-BN coatings are soaked, ions dissociated can easily diffuse to the coatings. The metaphosphates formed under annealing conditions seals the pores and increases the compactness of the coating [35].
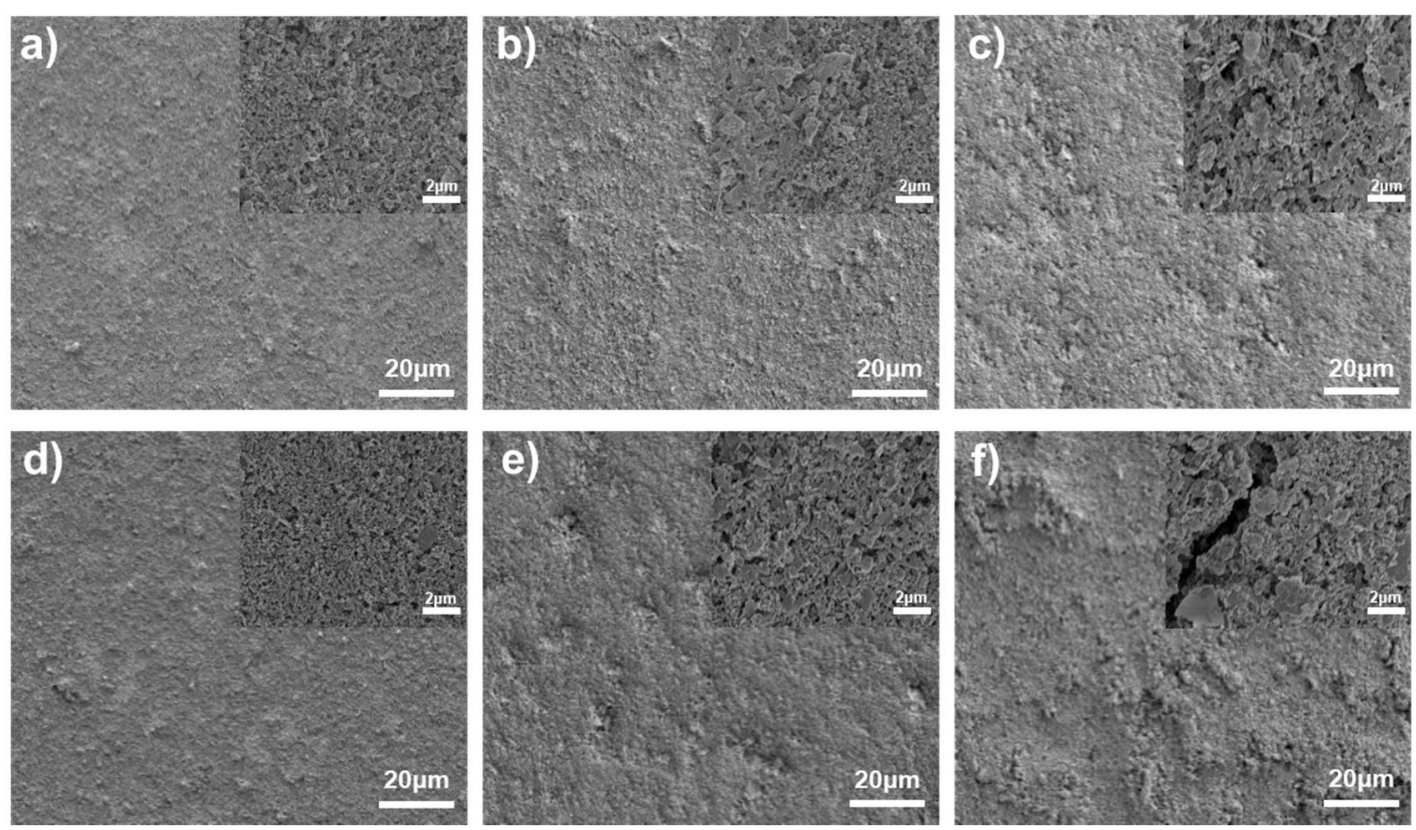

Figure 11. SEM images of h-BN coatings after dip-annealing treatment under different deposition conditions. (a) $15 \mathrm{~V}$ $10 \mathrm{~min}$; (b) $30 \mathrm{~V} 10 \mathrm{~min}$; (c) $50 \mathrm{~V} 10 \mathrm{~min}$; (d) $30 \mathrm{~V} 8 \mathrm{~min}$; (e) $30 \mathrm{~V} 12 \mathrm{~min}$; (f) $30 \mathrm{~V} 16 \mathrm{~min}$.

The element uniformity in the post-treated h-BN coating is shown by EDS maps presented in Figure 12a, with the bright spots indicating the presence of some related, 
respectively. As shown in Figure 12b, it is apparent that the two elements of phosphorus and aluminum are dispersed uniformly. The molar ratio of aluminum and phosphorus is $0.51 / 2.64$, although it does not completely match the ratio of the two elements in $\mathrm{Al}\left(\mathrm{H}_{2} \mathrm{PO}_{4}\right)_{3}$. These element distribution maps prove that $\mathrm{Al}\left(\mathrm{H}_{2} \mathrm{PO}_{4}\right)_{3}$ diffuses successfully into the coating.

a)

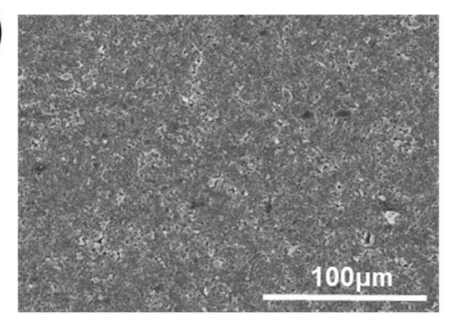

$\mathrm{O} K \alpha 1$

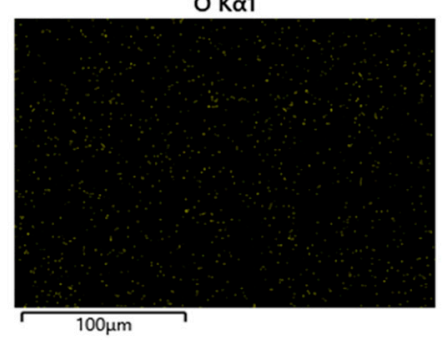

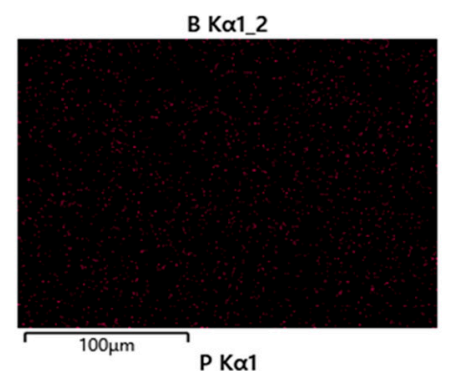

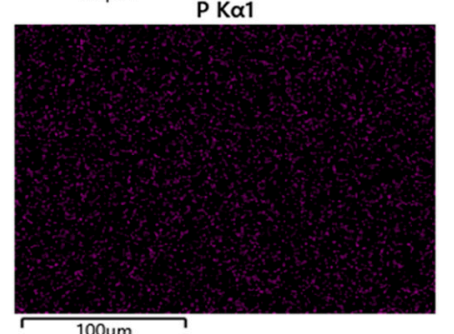

$100 \mu \mathrm{m}$
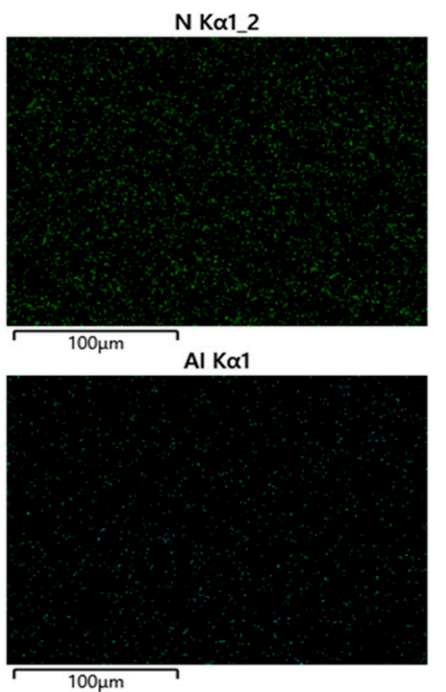

b)

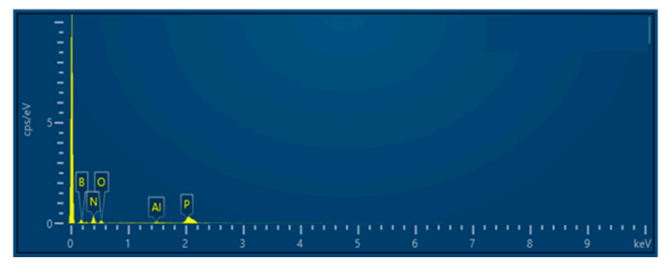

\begin{tabular}{ccc}
\hline Element & wt \% & at.\% \\
\hline B & 42.45 & 51.12 \\
N & 42.06 & 39.10 \\
O & 8.15 & 6.63 \\
P & 6.28 & 2.64 \\
Al & 1.06 & 0.51 \\
\hline
\end{tabular}

Figure 12. SEM images and EDS spectra of the h-BN coating prepared by EPD using $30 \mathrm{~V}$ and 10 min after immersionannealing treatment. (a) Element distribution images; (b) element analysis chart.

\subsection{Adhesive Strength Test}

Figure 13 shows the effect of the $\mathrm{Al}\left(\mathrm{H}_{2} \mathrm{PO}_{4}\right)_{3}$ concentration on the adhesive strength of the post-treated coatings under the same deposition, annealing and test conditions. The $\mathrm{Al}\left(\mathrm{H}_{2} \mathrm{PO}_{4}\right)_{3}$ solution entering the coating can form metaphosphates as a binder at high temperature to strengthen the adhesion between the stainless steel and the coating [36,37]. As observed in Figure 13a, the adhesive strength increases gradually with the increasing $\mathrm{Al}\left(\mathrm{H}_{2} \mathrm{PO}_{4}\right)_{3}$ concentration from 0.05 to $0.2 \mathrm{~mol} / \mathrm{L}$ and then decreases with the concentration from 0.2 to $0.4 \mathrm{~mol} / \mathrm{L}$. It could be seen that the adhesive strength of the coating soaked in a $0.2 \mathrm{~mol} / \mathrm{L}$ solution is the highest, presenting the least damage on the coating surface in Figure $12 \mathrm{~b}, \mathrm{c}$. Compared to the coating with the best adhesion, it is clear that the coatings soaked in 0.05 and $0.1 \mathrm{~mol} / \mathrm{L}$ solutions show obvious cracking and peeling since a lower concentration solution could diffuse ions into the coating with a lower rate. Moreover, the coatings soaked in a solution higher than $0.2 \mathrm{~mol} / \mathrm{L}$ still showed slight peeling off after the adhesion test. This peeling off could be caused by a solution with higher viscosity that slows down the diffusion of ions and decreases the content of metaphosphate. 
(a)

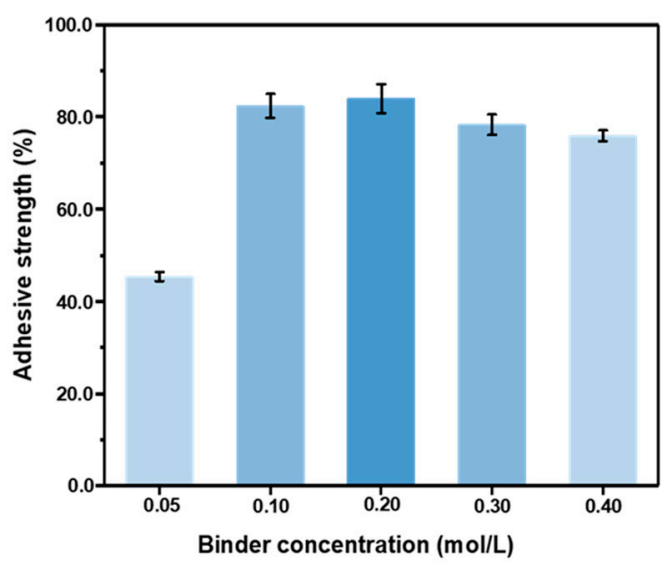

(c)

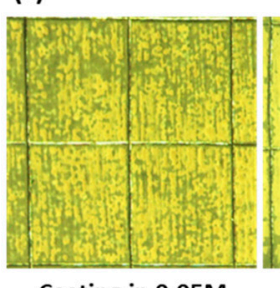

Coating in $0.05 \mathrm{M}$

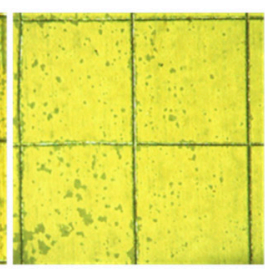

Coating in $0.1 \mathrm{M}$

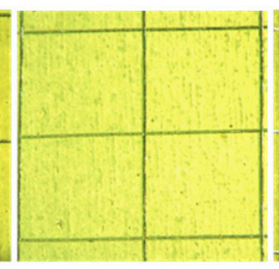

Coating in $0.2 \mathrm{M}$ (b) EPD samples

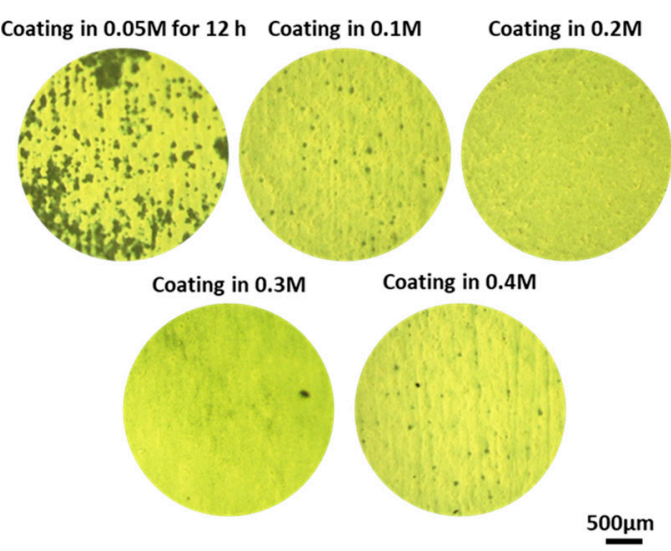

$500 \mu \mathrm{m}$

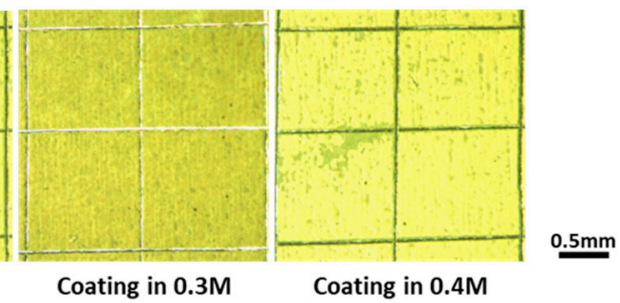

Figure 13. Adhesive strength of the coating soaked in $\mathrm{Al}\left(\mathrm{H}_{2} \mathrm{PO}_{4}\right)_{3}$ solution with different concentrations varying from 0.05 to $0.4 \mathrm{~mol} / \mathrm{L} \mathrm{(a)}$, corresponding microscopic images of the coatings after the adhesive strength test (b) and images of the coatings after the cross-hatching tests (c).

Figure 14 shows the effect of EPD voltage on the adhesive strength of the post-treated coatings deposited for $10 \mathrm{~min}$ and soaked in $0.2 \mathrm{~mol} / \mathrm{L} \mathrm{Al}\left(\mathrm{H}_{2} \mathrm{PO}_{4}\right)_{3}$ solution under the same conditions of annealing and test. As shown in Figure 14a, the adhesive strength of the coatings decreases distinctly as the deposition voltage increases, mainly owing to uneven and loose structures of the post-treated coating caused by fast migration of the flake h-BN particle at a higher voltage. The process of soaking and annealing cannot repair the loose coating structure, leading to the cracking and peeling-off of the edges of the coating after the test, as shown in Figure 14b,c.

Figure 15a shows the relationship between the adhesive strength of the coating and the EPD time. The corresponding microscope images of the coatings after the adhesion test are shown in Figure 15b. The post-treated coatings deposited at $30 \mathrm{~V}$ for different times were soaked in a $0.2 \mathrm{~mol} / \mathrm{L} \mathrm{Al}\left(\mathrm{H}_{2} \mathrm{PO}_{4}\right)_{3}$ solution under the same annealing conditions. It could be seen from Figure 15a that the adhesive strength of the coatings deposited for $8 \mathrm{~min}$ is closer to the other one deposited for $10 \mathrm{~min}$. As the deposition time increases, the adhesive strength of the coating decreases. The adhesive strength reaches the highest value at $10 \mathrm{~min}$, which is $83.9 \%$. Since the thick coating could inhibit the migration of h-BN particles in an electric field, some nanoparticles were deposited with an irregular state and formed a loose structure on the surface of the coating. The decreased adhesive strength caused by a large number of loose structures results in the peeling-off of the coating after the test, as observed in Figure 15b,c. 
(a)

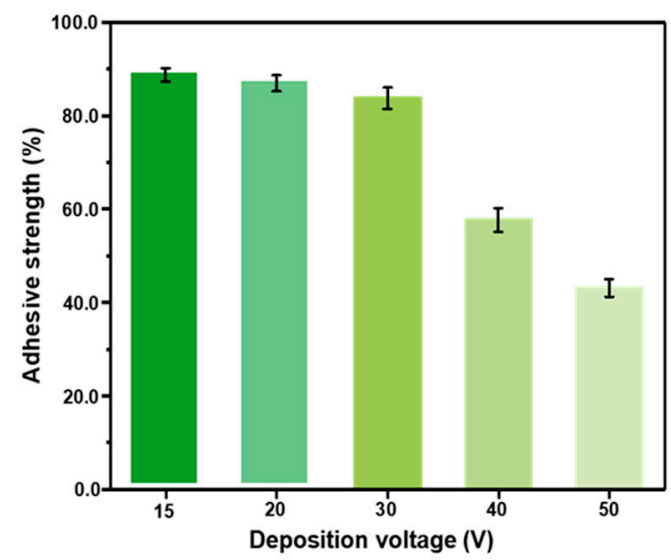

(b) EPD samples

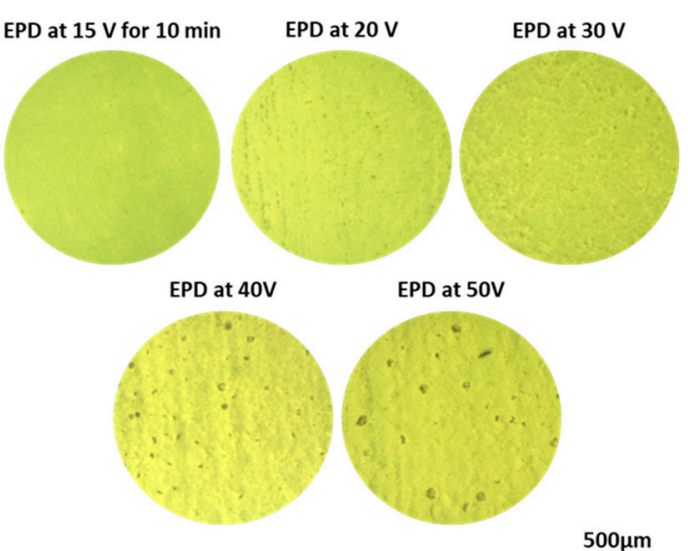

(c)

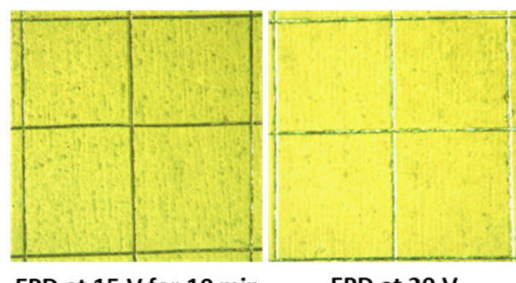

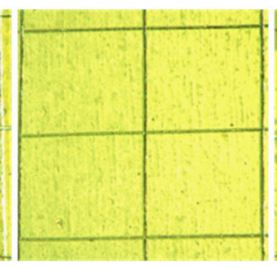

EPD at $30 \mathrm{~V}$

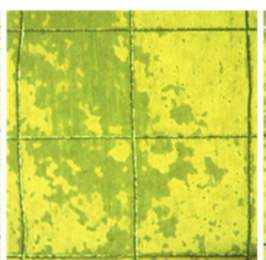

EPD at $40 \mathrm{~V}$

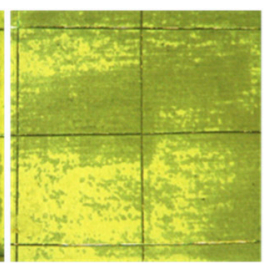

EPD at $50 \mathrm{~V}$

Figure 14. Adhesive strength of the post-treated coatings deposited at different voltages varying from 15 to $50 \mathrm{~V}$ (a), corresponding microscopic images of the coatings after the adhesive strength test (b) and images of the coatings after the cross-hatching tests $(\mathbf{c})$.

(a)

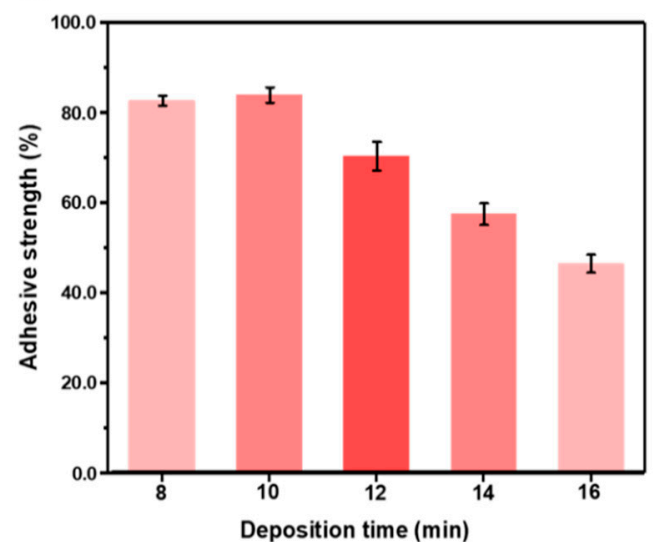

(c)

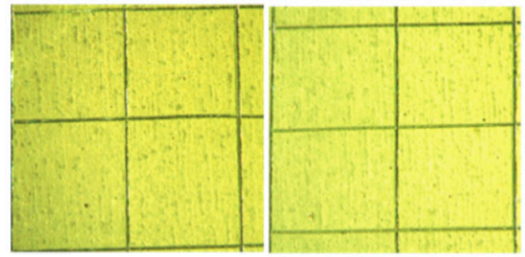

EPD at $30 \mathrm{~V}$ for $8 \mathrm{~min}$

EPD for $10 \mathrm{~min}$

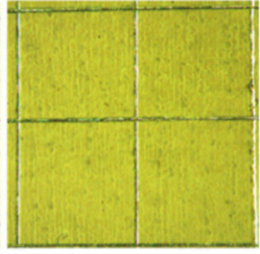

EPD for $12 \mathrm{~min}$ (b) EPD samples

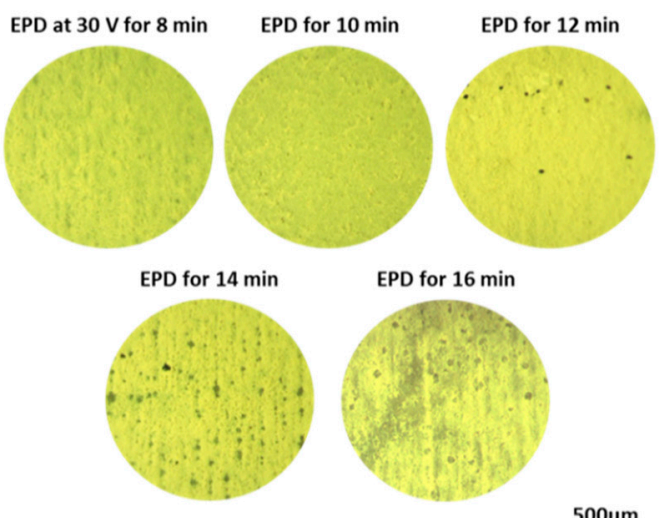

$500 \mu \mathrm{m}$

Figure 15. Adhesive strength of the post-treated coatings deposited for a different time during 8 to 16 min (a), corresponding microscopic images of the coatings after the adhesive strength test (b) and images of the coatings after the cross-hatching tests (c). 


\subsection{Heat Resistance Test of Coating}

The uniform and crack-free h-BN coatings surfaces were obtained by EPD. To determine that the coating can withstand high temperatures, the soaked sample were annealed with an appropriate heating rate. Figure 16 shows the surface of the boron nitride coating at different temperatures. There are no obvious cracks and color changes on the surface of the annealed h-BN coatings. $\mathrm{Al}\left(\mathrm{H}_{2} \mathrm{PO}_{4}\right)_{3}$ forms different crystalline metaphosphates and phosphates with strong adhesion at higher temperatures. The properties of the two materials determine that the coating can withstand high temperatures.

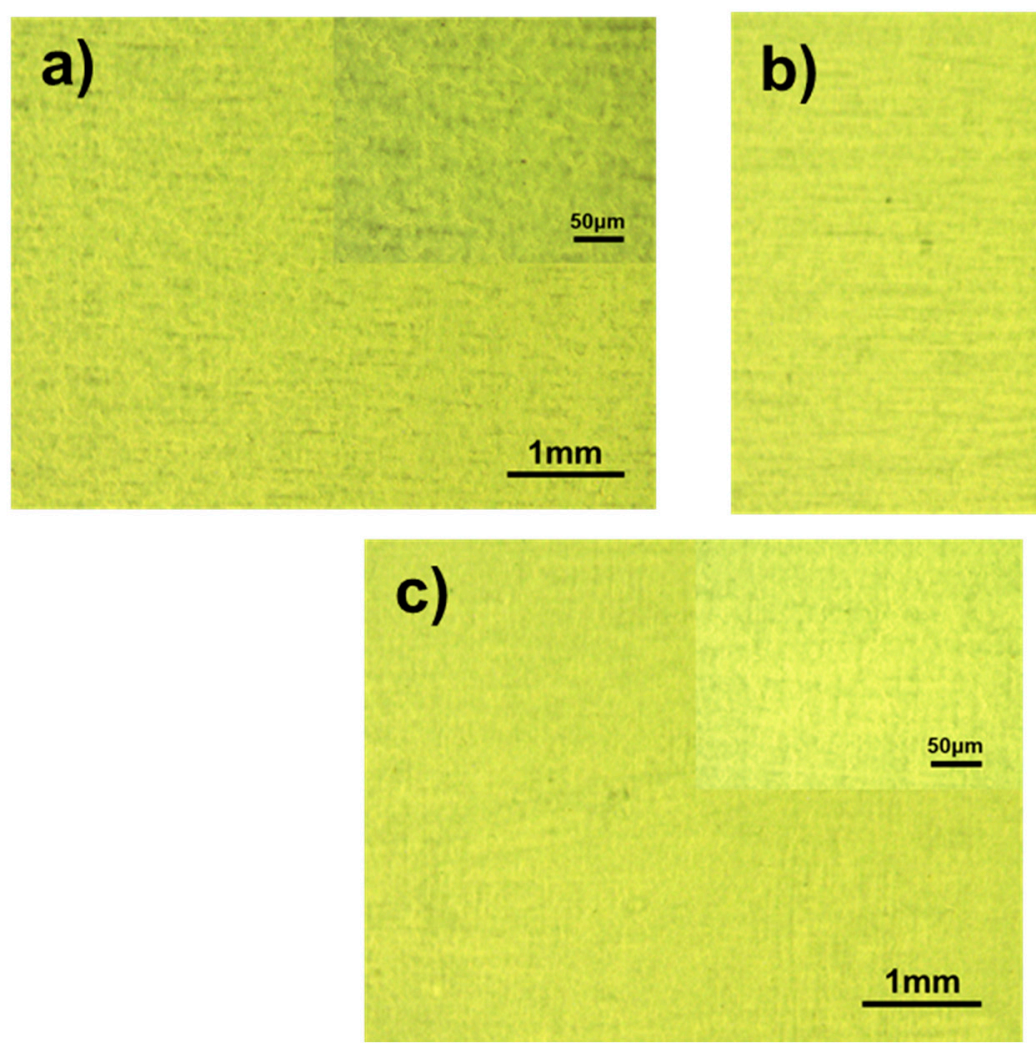

Figure 16. Images of h-BN coatings annealed at $400\left(\right.$ a), $600\left(\right.$ b) and $800{ }^{\circ} \mathrm{C}$ (c).

\subsection{Breakdown Test of Coating}

When the applied voltage is as high as a certain value, the dielectric loss or breakdown occurs due to the inability of the electrically insulating material to withstand extreme conditions. This voltage is called the breakdown voltage. The breakdown strength of an insulating coating is defined as the ratio of the breakdown voltage to the thickness of the coating.

Figure 17 shows the effect of EPD time on the thickness, breakdown voltage and breakdown strength of the coating. The post-treated coatings deposited at $30 \mathrm{~V}$ for different times were soaked in a $0.2 \mathrm{~mol} / \mathrm{L} \mathrm{Al}\left(\mathrm{H}_{2} \mathrm{PO}_{4}\right)_{3}$ solution under the same annealing conditions. With an increase in EPD time, the thickness of the post-treated coating increases. The breakdown voltage increases with the EPD time from 8 to $10 \mathrm{~min}$, and then decreases with the EPD time from 10 to $16 \mathrm{~min}$. The breakdown voltage of the coating under the EPD time of $10 \mathrm{~min}$ is the highest, which is $1.22 \mathrm{kV}$. Under a long period of deposition, the loose structure is formed inside the coating due to the irregular deposition of $\mathrm{h}$-BN particles. This is unfavorable for the formation of a dense insulating medium with high voltage resistance. Based on the above two sets of data, we can obtain the relationship between the EPD time and the breakdown strength of the coating. The results indicate that the breakdown strength decreases with an increase in EPD time. The coating prepared under 
the EPD time of 10 min can achieve an excellent balance between suitable thickness and compact structure, showing the highest breakdown voltage and great breakdown strength.

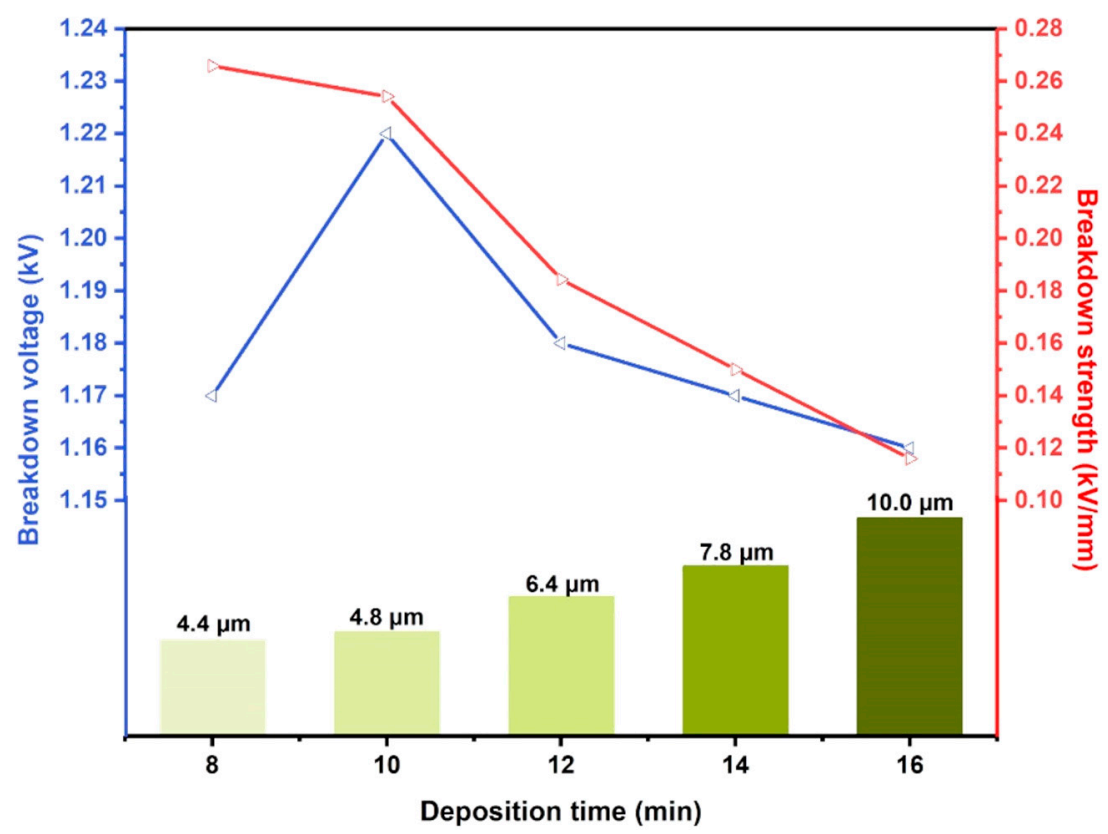

Figure 17. Thickness, breakdown voltage and breakdown strength of the treated h-BN coatings prepared by EPD at $30 \mathrm{~V}$ as a function of deposition time ( 8 to $16 \mathrm{~min}$ ).

\section{Conclusions}

We have combined the EPD, inorganic binder and sintering process to prepare h-BN coating on SS316L stainless steel substrate to make up for the problems of traditional insulating coating. After the inorganic binder immersion and annealing treatment, the adhesion between the insulating coating and the stainless steel substrate increases. The h-BN coating deposited at $30 \mathrm{~V}$ for $10 \mathrm{~min}$ has a uniform surface, a suitable thickness and a relatively compact structure. Through the corresponding experiment, the appropriate concentration of the inorganic binder was selected, which was $0.2 \mathrm{~mol} / \mathrm{L}$. Through the adhesion test, the coatings after soaking and sintering showed good adhesion, and the adhesive strength was $83.9 \%$. In addition to having good heat resistance, the coating prepared under this condition also has good insulation, with the highest breakdown voltage of $1.22 \mathrm{kV}$ and excellent breakdown strength of $0.254 \mathrm{kV} / \mathrm{mm}$. In summary, this method can shorten the preparation cycle of the h-BN coatings, thereby obtaining a thicker and denser ceramic coating, with ideal and controllable performance, and showing the potential for insulation applications. This method can be used to prepare high-performance inorganic ceramic materials.

Author Contributions: Methodology, K.J.; data curation, X.M. and K.J.; writing-original draft preparation, K.J.; writing - review and editing, K.J. and W.W.; project administration, X.M.; funding acquisition, W.W. All authors have read and agreed to the published version of the manuscript.

Funding: This research received no external funding.

Institutional Review Board Statement: Not applicable.

Informed Consent Statement: Not applicable.

Data Availability Statement: All data used to support the findings of this study are included within the article.

Conflicts of Interest: The authors declare no conflict of interest. 


\section{References}

1. Xiaorui, Z.; Liu, L.; Ling, W. Preparation of water-soluble electrical steel coating with $\mathrm{SiO}_{2}$ modified by glycine. Polym. Compos. 2018, 39, 1255-1260. [CrossRef]

2. Hou, C.K.; Wang, P.C. Effects of composition and process variables on core loss and hardness of low carbon electrical steels. J. Magn. Magn. Mater. 1990, 92, 109-115. [CrossRef]

3. Lin, A.; Zhang, X.; Fang, D.; Miao, Y. Study of an environment-friendly insulating coating with high corrosion resistance on electrical steel. Anti-Corros. Methods Mater. 2010, 57, 297-304. [CrossRef]

4. Tangab, N.J.; Jianga, H.Y.; Zhonga, W.; Wua, X.L.; Zoua, W.Q.; Du, Y.W. Synthesis and magnetic properties of Fe $/ \mathrm{SiO}_{2}$ nanocomposites prepared by a sol-gel method combined with hydrogen reduction. J. Alloys Compd. 2006, 419, 145-148. [CrossRef]

5. Taghvaei, A.H.; Shokrollahi, H.; Ghaffari, M.; Kamal, J. Influence of particle size and compaction pressure on the magnetic properties of iron-phenolic soft magnetic composites. J. Phys. Chem. Solids 2010, 71, 7-11. [CrossRef]

6. Kandel, H.; Lu, J.; Jiang, J.; Han, K.; Gundlach, S.; Viouchkov, Y.; Markiewicz, W.D.; Weijers, H. Sol-gel-Derived Composite Coating for Electrical Insulation in HTS Magnet Technology. IEEE Trans. Appl. Supercond. 2012, 22, 7701605. [CrossRef]

7. Hemmati, I.; Hosseini, H.; Miraghaei, S. Effect of processing parameters on electrical, mechanical and magnetic properties of iron-resin soft magnetic composite. Powder Metall. 2007, 50, 86-90. [CrossRef]

8. Pang, Y.X.; Hodgson, S.; Weglinski, B.; Gaworska, D. Investigations into sol-gel silica and silica hybrid coatings for electromagnetic soft magnetic composite applications. J. Mater. Sci. 2006, 41, 5926-5936. [CrossRef]

9. Luo, R.; Li, P.; Wei, H.; Hui, C.; Kun, Y. Structure and electrical insulation characteristics of plasma-sprayed alumina coatings under pressure. Ceram. Int. 2017, 44, 6033-6036. [CrossRef]

10. Tong, L.; Zhang, F.; Xue, C.; Lan, L. Structure stability and corrosion resistance of nano-TiO 2 coatings on aluminum in seawater by a vacuum dip-coating method. Surf. Coat. Technol. 2010, 205, 2335-2339.

11. Li, Y.Q.; Yu, Z.N.; Jian, L.; Dong, P.Z.; She, C.; Gang, J. Electrical insulation and bending properties of $\mathrm{SiO}_{\mathrm{x}}$ barrier layers prepared on flexible stainless steel foils by different preparing methods. Thin Solid Films 2011, 519, 4234-4238. [CrossRef]

12. Kruk, A.; Zimowski, S.; Łukaszczyk, A.; Cieniek, Ł.; Moskalewicz, T. The influence of heat treatment on the microstructure, surface topography and selected properties of PEEK coatings electrophoretically deposited on the Ti-6Al-4V alloy-ScienceDirect. Prog. Org. Coat. 2019, 133, 180-190. [CrossRef]

13. Koh, A.; Chen, T.; Pan, L.; Zhuo, S.; Daniel, H.C.C. Effective hybrid graphene/carbon nanotubes field emitters by electrophoretic deposition. J. Appl. Phys. 2013, 113, 174909. [CrossRef]

14. Boccaccini, A.; Chicatun, F.; Cho, J.; Bretcanu, O.; Roether, J.A.; Novak, S.; Chen, Q.Z. Carbon Nanotube Coatings on BioglassBased Tissue Engineering Scaffolds. Adv. Funct. Mater. 2010, 17, 2815-2822. [CrossRef]

15. Mazor, H.; Golodnitsky, D.; Burstein, L.; Gladkich, A. Electrophoretic deposition of lithium iron phosphate cathode for thin-film 3D-microbatteries. J. Power Source 2012, 198, 264-272. [CrossRef]

16. He, W.; Krejci, A.; Lin, J.; Osmulski, M.E.; Dickerson, J.H. A facile synthesis of Te nanoparticles with binary size distribution by green chemistry. Nanoscale 2011, 3, 1523-1525. [CrossRef]

17. Nagarajan, R.; Ganesh, K. Block copolymer self-assembly in selective solvents: Theory of solubilization in spherical micelles. Macromolecules 1989, 22, 4312-4325. [CrossRef]

18. Fan, Y.; Yang, H.; Fan, H.; Qi, L.; Chuang, L.; Xue, Z.; Mingxu, Y.; Jianjun, W.; Xiaoming, C. Corrosion Resistance of Modified Hexagonal Boron Nitride (h-BN) Nanosheets Doped Acrylic Acid Coating on Hot-Dip Galvanized Steel. Materials 2020, 13, 2340. [CrossRef]

19. Tozar, A.; Karahan, S.H.; Yücel, Y. Optimization of the Electrophoretic Deposition Parameters for Biocomposite Hydroxyapatite/ Chitosan/Collagen/h-BN Coatings on Ti6Al4V Biomedical Implants. Metall. Mater. Trans. A 2018, 50A, 1009-1020. [CrossRef]

20. Hattori, Y.; Taniguchi, T.; Watanabe, K.; Kosuke, N. Layer-by-Layer Dielectric Breakdown of Hexagonal Boron Nitride. ACS Nano 2015, 9, 916-921. [CrossRef]

21. Li, L.H.; Chen, Y. Atomically Thin Boron Nitride: Unique Properties and Applications. Adv. Funct. Mater. 2016, 26, 2594-2608. [CrossRef]

22. Huang, K.; Liang, L.; Chai, S.; Uma, T.; Meijun, L.; Zili, W.; Bobby, G.; Sumpter, S.D. Aminopolymer functionalization of boron nitride nanosheets for highly efficient capture of carbon dioxide. J. Mater. Chem. A 2017, 5, 16241-16248. [CrossRef]

23. Anota, E.C.; Juárez, A.R.; Castro, M.; Hernández-Cocoletzi, H. A density functional theory analysis for the adsorption of the amine group on graphene and boron nitride nanosheets. J. Mol. Modeling 2013, 19, 321-328. [CrossRef] [PubMed]

24. Cao, F.; Ren, W.; Ji, Y.M.; Zhao, C. The structural and electronic properties of amine-functionalized boron nitride nanotubes via ammonia plasmas: A density functional theory study. Nanotechnology 2009, 20, 145703.

25. Wattanakul, K.; Manuspiya, H.; Yanumet, N. The adsorption of cationic surfactants on BN surface: Its effects on the thermal conductivity and mechanical properties of BN-epoxy composite. Colloids Surf. A Physicochem. Eng. Asp. 2010, 369, 203-210. [CrossRef]

26. Wang, G.; Sarkar, P.; Nicholson, P.S. Influence of Acidity on the Electrostatic Stability of Alumina Suspensions in Ethanol. J. Am. Ceram. Soc. 2010, 80, 965-972. [CrossRef]

27. Zeng, Q.; Wan, W.; Chen, L. Enhanced Mechanical and Electrochemical Performances of Silica-Based Coatings Obtained by Electrophoretic Deposition. ACS Appl. Mater. Interfaces 2019, 11, 24308-24317. [CrossRef] [PubMed] 
28. Nithya, J.M.; Pandurangan, A. Aqueous dispersion of polymer coated boron nitride nanotubes and their antibacterial and cytotoxicity studies. RSC Adv. 2014, 4, 32031-32046. [CrossRef]

29. Qiu, W.Z.; Yang, H.C.; Wan, L.S.; Zhi-Kang, X. Co-deposition of catechol/polyethyleneimine on porous membranes for efficient decolorization of dye water. J. Mater. Chem. A 2015, 3, 14438-14444. [CrossRef]

30. Yapncak, G.; Merve, G.; Feray, B.; Nuran, A. Electrophoretic deposition of hydroxyapatite-hexagonal boron nitride composite coatings on Ti substrate. Mater. Sci. Eng. C 2017, 79, 343-353.

31. Peiwen, W.; Wenshuai, Z.; Yanhong, C.; Jinshui, Z.; Pengfei, Z.; Huiyuan, Z.; Changfeng, L.; Zhigang, C.; Huaming, L.; Sheng, D. A template-free solvent-mediated synthesis of high surface area boron nitride nanosheets for aerobic oxidative desulfurization. Chem. Commun. 2016, 52, 144-147.

32. Liu, F.; Huang, K.; Yoo, C.J.; Claudia, O.; Duan-Jian, T.; Christopher, W.J.; Sheng, D. Facilely Synthesized Meso-Macroporous Polymer as Support of Poly(ethyleneimine) for Highly Efficient and Selective Capture of $\mathrm{CO}_{2}$. Chem. Eng. J. 2017, 314, 466-476. [CrossRef]

33. Jiang, F.; Zhao, W.; Wu, Y.; Lu, S.; Xiaojing, C.; Yanlin, H. A polyethyleneimine-grafted graphene oxide hybrid nanomaterial: Synthesis and anti-corrosion applications. Appl. Surf. Sci. 2019, 479, 963-973. [CrossRef]

34. Hamaker, H. Formation of deposition by electrophoresis. Trans. Faraday. Soc. 1940, 36, 279-283. [CrossRef]

35. Vetrivendan, E.G.; Madhura, B.; Jagadeeswara Rao, C.; Ningshen, S. Aluminum phosphate sealing to improve insulation resistance of plasma-sprayed alumina coating. Mater. Manuf. Process. 2017, 32, 1435-1441. [CrossRef]

36. Chung, D. Acid aluminum phosphate for the binding and coating of materials. J. Mater. Sci. 2003, 38, 2785-2791. [CrossRef]

37. Knuuttila, J.; Sorsa, P.; Mntyl, T.; Knuuttila, J.; Sorsa, P. Sealing of thermal spray coatings by impregnation. J. Therm. Spray Technol. 1999, 8, 249-257. [CrossRef] 